\title{
DOE|PC/88890-T.7
}

$\mathrm{DOE} / \mathrm{PC} / 88890--\mathrm{T} 7$

DE92 016150

\section{PROOF OF CONCEPT TESTING OF AN INTEGRATED DRY INJECTION SYSTEM FOR SO2/NOX CONTROL}

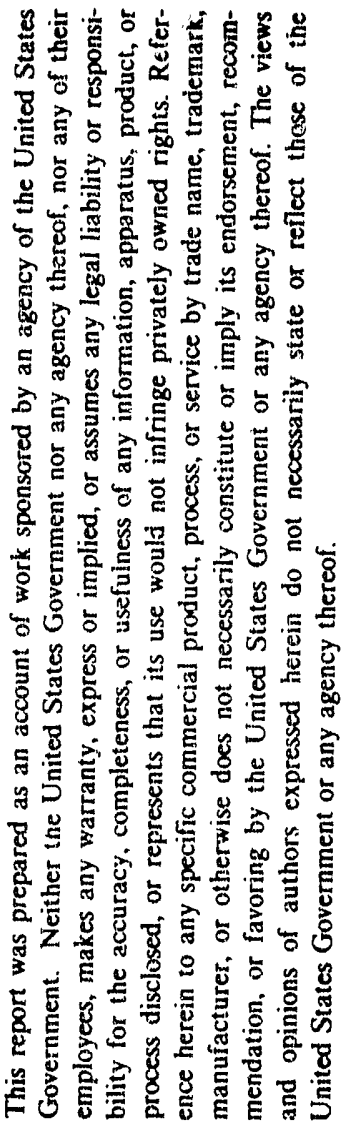

\author{
Quarterly Technical Progress Report \\ October - December, 1991 \\ Prepared by \\ D. J. Helfritch and S. J. Bortz \\ Research-Cottrell \\ and \\ R. Beittel \\ Riley Stoker Corp.
}

DOE Contract No. DE AC22 88PC88890

\section{MASTER}




\section{INTRODUCTION}

The parametric test program was carried out in the time period covered by this report. Three coals and four sorbents were used in the testing. SO2 removal, NOx removal, and precipitator performance were all investigated. The test matrix is given in Table 1.

\section{ACTIVITY}

Testing in October concentrated on SO2 removal resulting from hydrate injection and precipitator baseline performance. Typical results for operation on Dctober 30 are shown in Figure 1. Hydrate injection at $1030 \mathrm{deg} F$ for various $\mathrm{Ca} / \mathrm{S}$ mole ratios are shown. It is seen that increasing hydrate mole ratios yield decreasing outlet S02 concentrations. Also shown is the precipitator exit opacity, and it can be seen that increasing hydrate injection rates lead to larger opacities.

Figure 2 reduces the data of Figure 1 to show $\mathrm{SO} 2$ removal as a function of $\mathrm{Ca} / \mathrm{S}$ ratio. It should be pointed out that subsequent adjustments to the hydrate injection nozzles have improved utilization by about $5 \%$ over that shown in Figue 2. Maxirnum achievable hydrate utilization has been about $30 \%$ at a $\mathrm{Ca} / \mathrm{S}$ of 2 . This utilization has been reached with optimum placements of either the vertical pipe injector system, or the horizontal injector system, see Figures $3 \& 4$.

Testing in November concentrated on SO2 and NOX removal resulting from combined hydrate and bicarbonate injection and the subsequent electrostatic precipitator impacts. Typical results for operation on November 14 are shown in Figure 5 . This Figure shows SO2 
concentration at the precipitator exit as a function of operating time. It is seen that initial SO2 concentration without sorbent injection is $1800 \mathrm{ppm}$. The initiation of hydrate injection at 20 minutes into the test yields a drop of 502 concentration to 700 $\mathrm{ppm}$. An additional decrease in 502 concentration to $200 \mathrm{ppm}$ results with the initiation of bicarb injection at 40 minutes. The system response to sorbent injection shown in this figure is typical of that seen for all testing to date.

Figure 6 shows SO2 removal as a function of Na2/S ratio, based on the sulfur concentration at the bicarb injection point. It is seen that $60 \%$ removal is intially obtained with hydrate injection only. and increasing bicarb injection results in more 502 removal, such that $90 \%$ removal is reached at a Na2/S ratio of 2.3 .

Figure 7 shows the results of the November 14 testing over a 280 minute time period. These tests were performed in order to characterize the effects of lowering the precipitator inlet temperature by humidification on precipitator performance and on overall SO2 removal. The figure shows precipitator inlet temicrature, SO2 and NOx removal percents, and precipitator exit opacity, all as functions of operating time. The temperature was decreased in steps from 300 deg $F$ to 170 degrees. Hydrate injection at $\mathrm{Ca} / \mathrm{S}=3$ was started at 20 minutes and bicarb injection at $\mathrm{Na} 2 / \mathrm{S}=2$ was started at 40 minutes. There were four interruptions of the hydrate feed. These occurred at $80,140,180$, and 230 minutes. The bicarb feed was continuous throughout the test. The viewpath of the opacity monitor was a longitudinal section of ductwork, and the opacity measurements are not calibrated to a stack but are taken for comparative purposes. 
It can be seen that opacity increases significantly when the hydrate feed is initiated and drops to its original, fly ash only value when the hydrate feed is interrupted. This indicates that precipitator performance is adversely affected by the hydrate but not by the bicarb. It is also seen that near original opacity is recovered when the inlet precipitator temperature is reduced to 220 $\operatorname{deg} F$, and further temperature lowering has no effect on opacity.

S02 removal increases as the temperature is reduced below 200 degrees, and an additional 5\% S02 removal can be realized at 170 degrees. It is likely that SO2 removal would continue to improve as the gas temperature approaches adiabatic saturation.

Approximately $10 \%$ to $20 \%$ NOx removal is achieved, and it is interesting to observe peaks in NOx removal at those points were the hydrate injection was interrupted. This is because the NOx reaction with sodium bicarbonate requires the participation of SO2, and hence the higher SO2 concentrations resulting from no hydrate injection gave rise to enhanced NOx removal.

Other testing done in November includes the injection of a commercialiy available, relatively low surface area hydrate, and the injection of sodium sesquicarbonate.

Testing in December concentrated on examining the effects of alternate coals and sorbents. Typical results are shown in Figure 8, which gives 502 removal while burning the program coal. This figure shows that $90 \%$ SO2 removal can be accomplished when $\mathrm{Ca} / \mathrm{S}=$ 3 and $\mathrm{Na} 2 / \mathrm{S}=1$. Both the $\mathrm{Ca} / \mathrm{S}$ and the $\mathrm{Na} 2 / \mathrm{S}$ mole ratios reported in Figure 8 are based on an inlet SO2 concentration of about 1900 ppm. 
Figure 9 shows the relative effectiveness of sodium sesquicarbonate injection versus sodium bicarbonate injection. The mole ratios reported in this figure are based on the $\mathrm{SO2}$ concentration at the point of sodium sorbent injection. It is seen that sodium bicarbonate is more effective than sesquicarbonate, with utilization about $8 \%$ higher.

Figure 10 shows how SO2 removal is affected by the SO2 inlet concentration supplied by the three different coals. As expected, higher $\mathrm{SO} 2$ removal is obtained at high $\mathrm{SO} 2$ concentration. The errant data point at $12 \%$ removal resulted from difficulty with the sorbent feed at the low feed rate.

\section{CONCLUSIONS AND FORECAST}

The test results have shown that $90 \%$ SO2 and 65\% NOx removal is possible with the Integrated Dry Injection Concept, al though higher than anticipated bicarb usage is required. It was also demonstrated that precipitator performance can be returned to pre-injection levels by evaporative cooling to 200 deg $F$. Other results have betil:

- The optimum injection temperature is 1000 deg $F$.

- Optimization of the hydrate/gas mixing can lead to utilization improvements up to $10 \%$.

- Some additional S02 removal can be achieved by means of humidification.

- Sodium bicarbonate achieves approximately $20 \%$ higher incremental $\mathrm{SO} 2$ removal than sesquicarbonate.

- Hydrate utilization improves as SO2 concentration increases. 
Activity in the next quarter will focus on a determination of the disposal options for the fly ash/sorbent waste material. A fixation technique will be evaluated. Also the data generated by the testing described here will be reduced and analyzed. Finally the test facility will be decommissioned for winter. 


\section{TABLE 1}

PROPOSED INTEGRATED DRY INJECTION TEST MATRIX

RUN NO. CONDITIONS ECON TEMP $\mathrm{Ca} / \mathrm{S}$

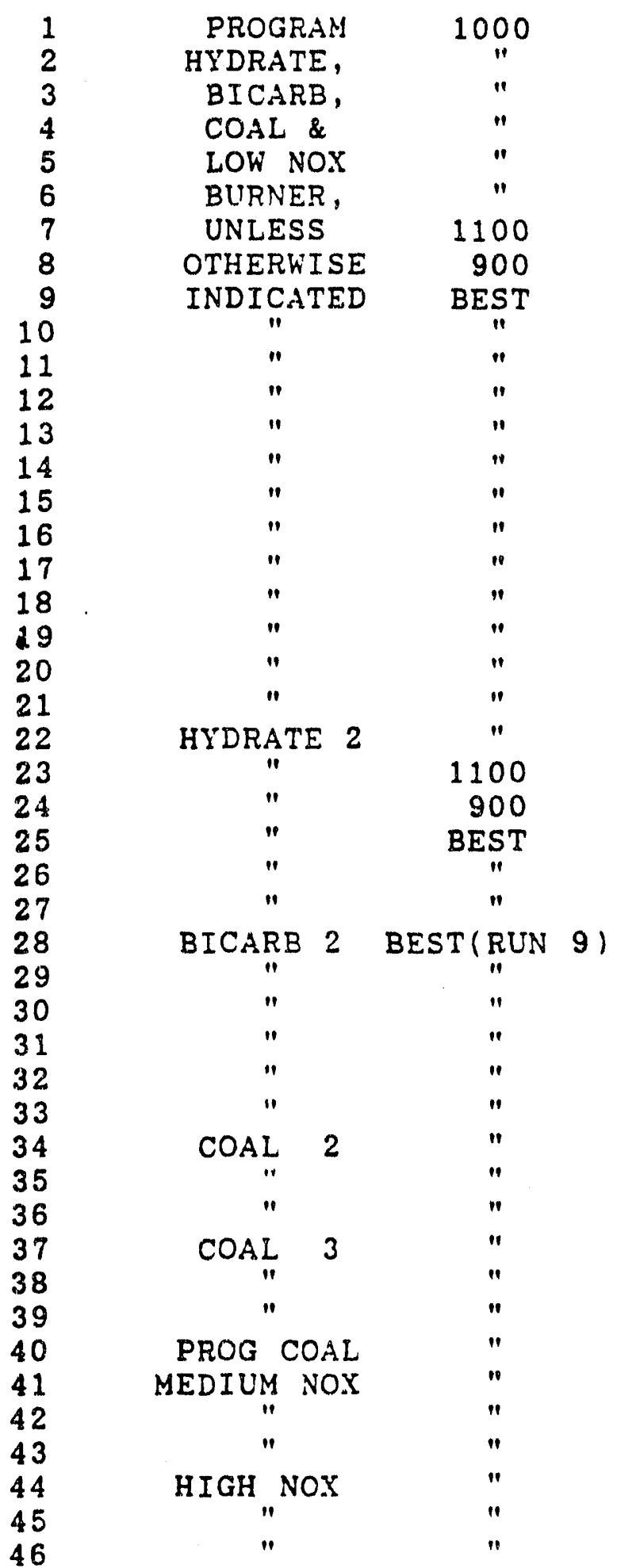

AH TEMP $2 \mathrm{Na} /(\mathrm{S}+2 \mathrm{NO})$ HUMID TEMP

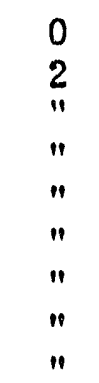

2.5

1.5

2

300
$" ~$
$"$
$"$
$"$
$"$
$"$
270
350
300

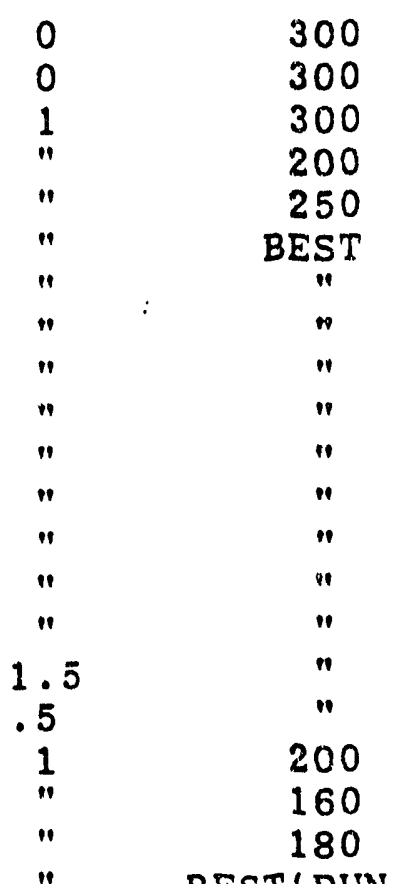

BEST (RUN 6)
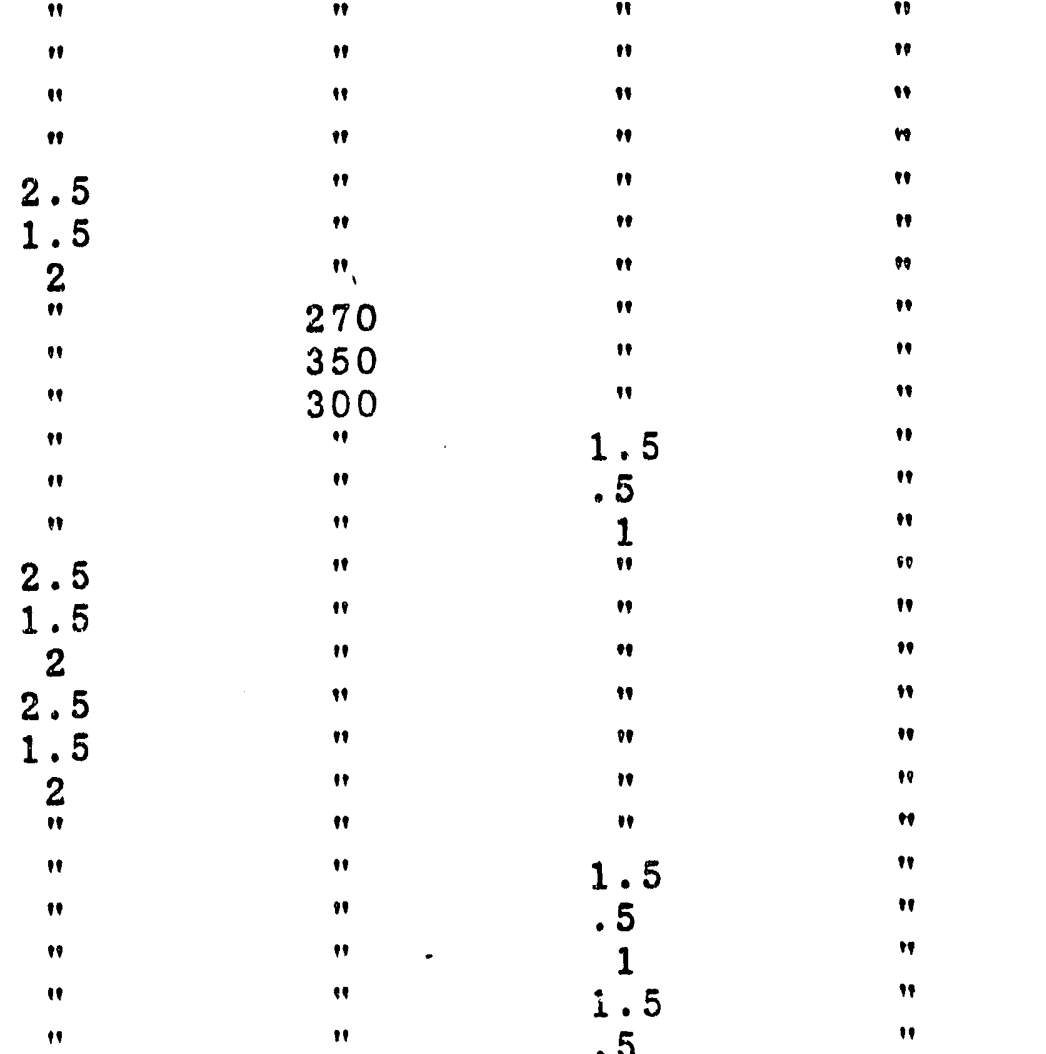


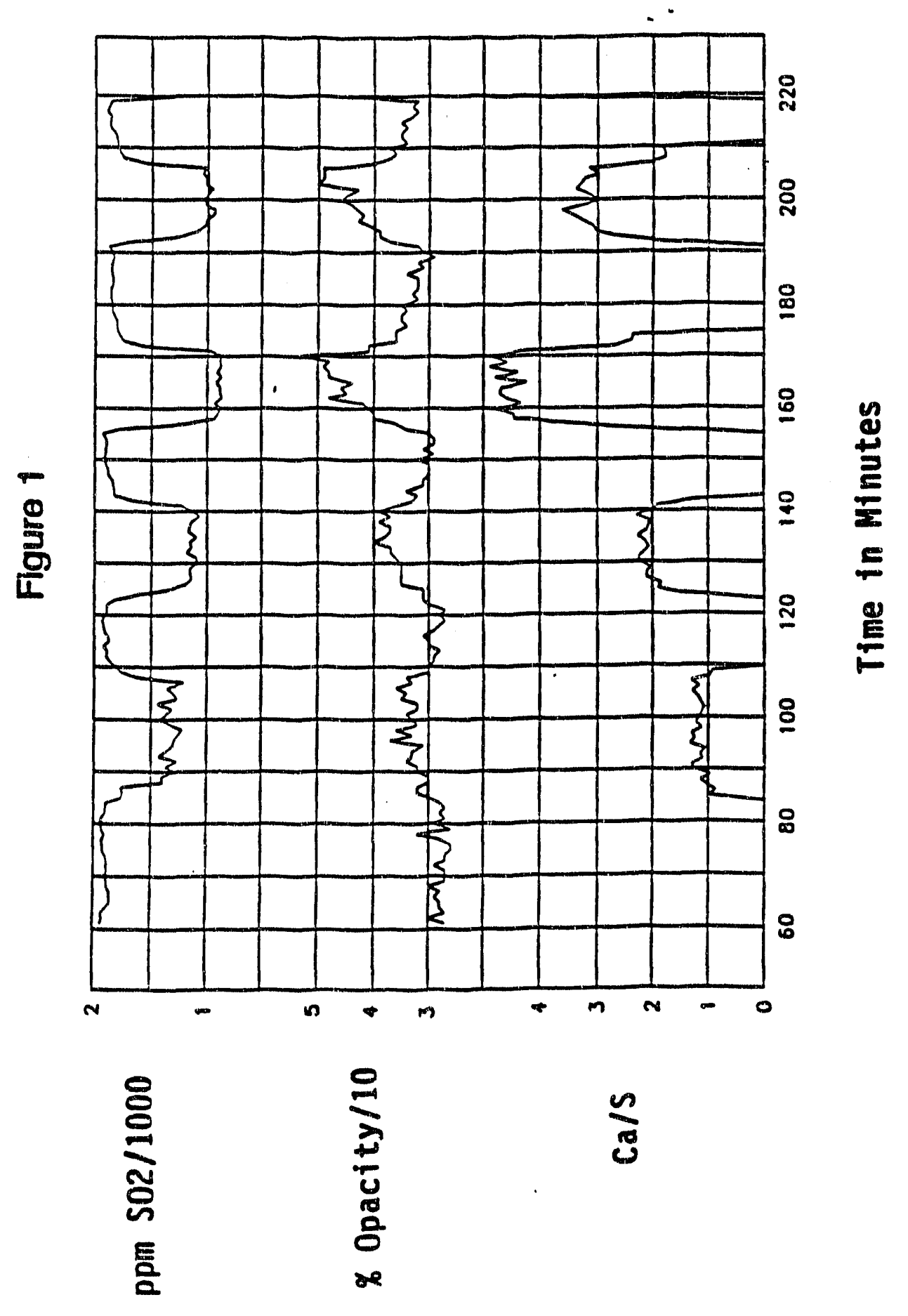




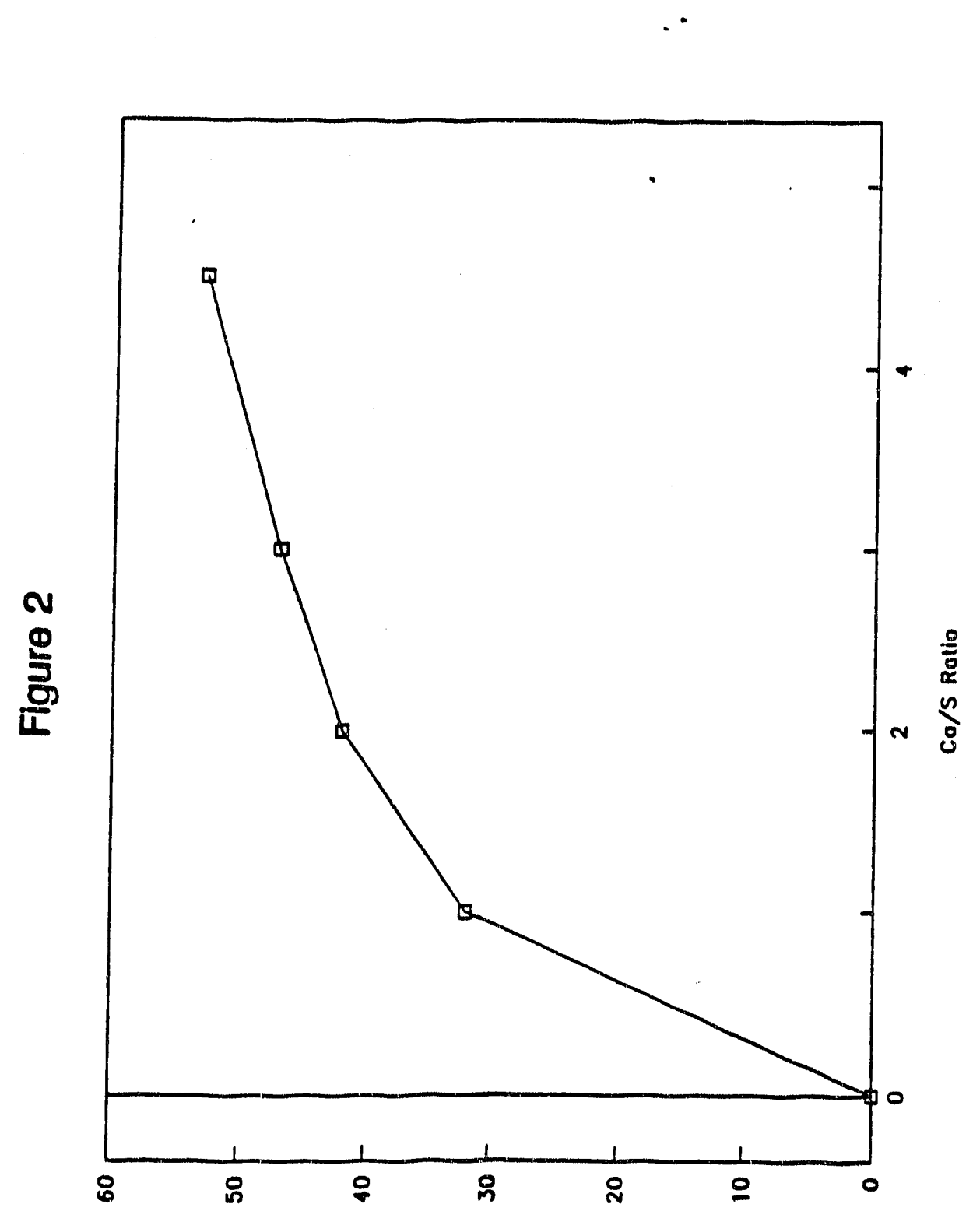

lonower zOS tuespod 

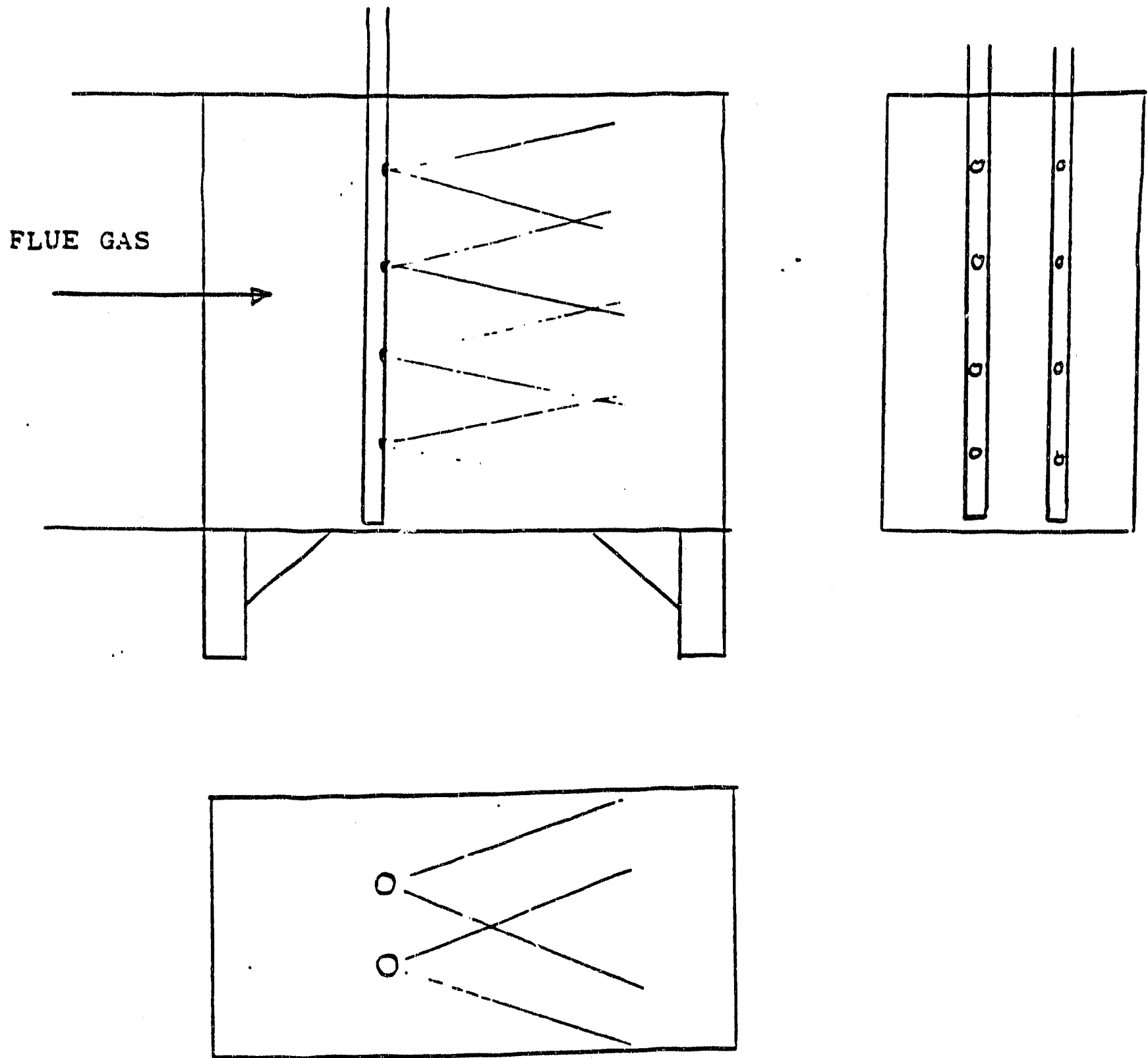

Figure 3

Injection System 1 Design

Two 2.5 " pipes with four $3 / 4$ " holes

Pipes can be rotated for co or countercurrent injection 

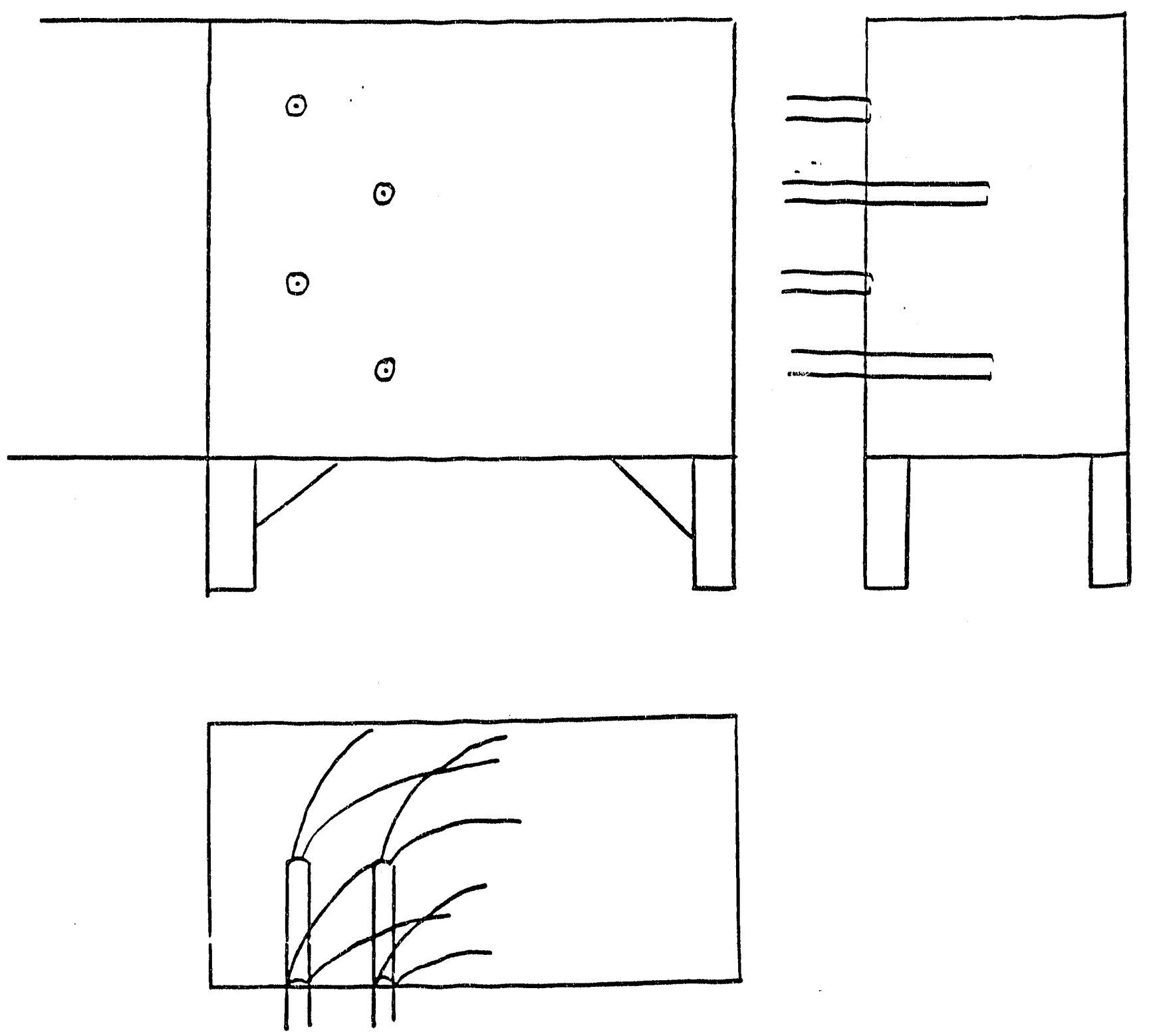

Figure 4

\section{Injection System 2 Design}

Four 2" pipes with $11 / 4 "$ nozzles

Depth of insertion adjustable for each injector 


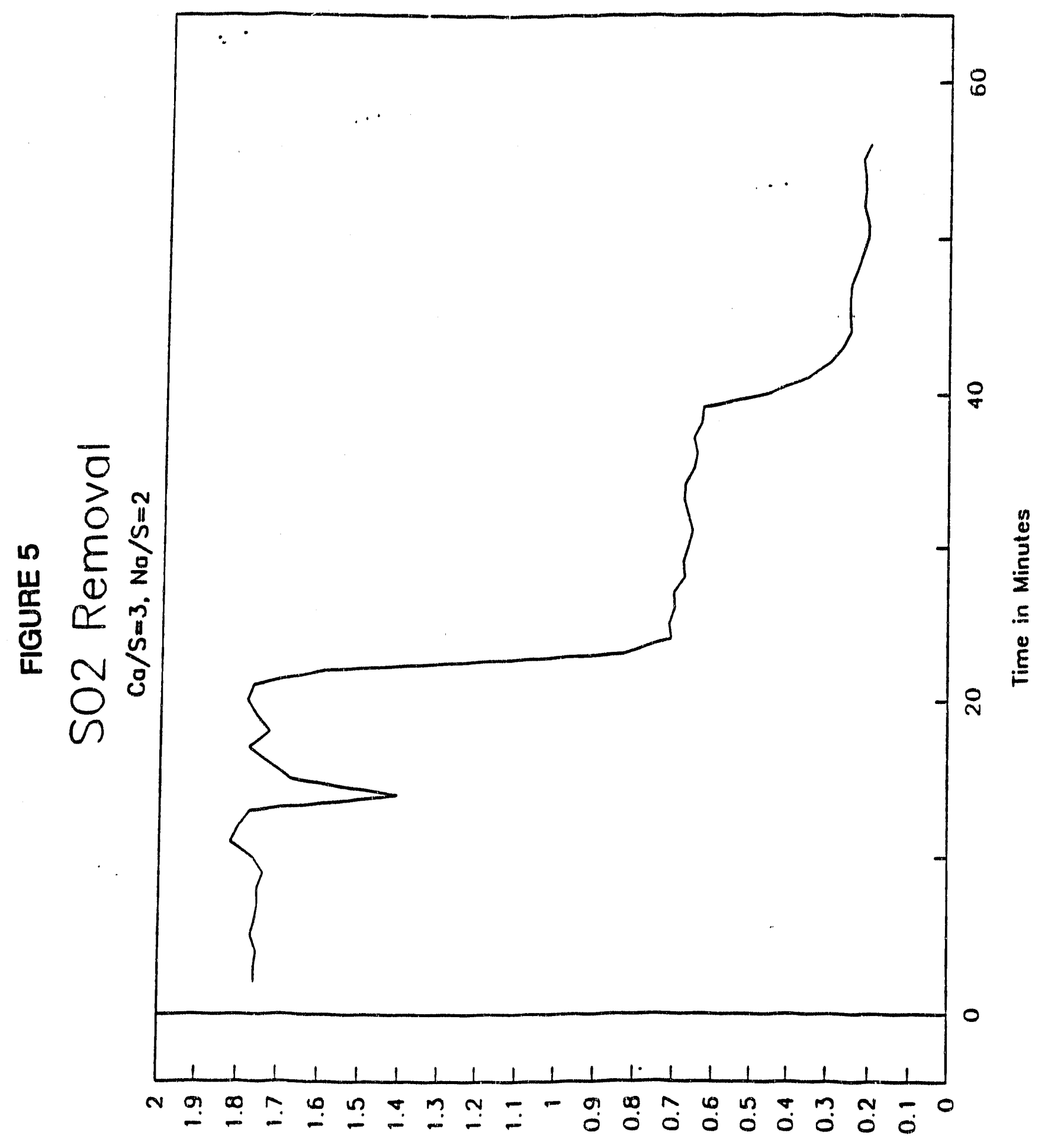

(spuosnoul)

wad wo!fodivajwos zOS 


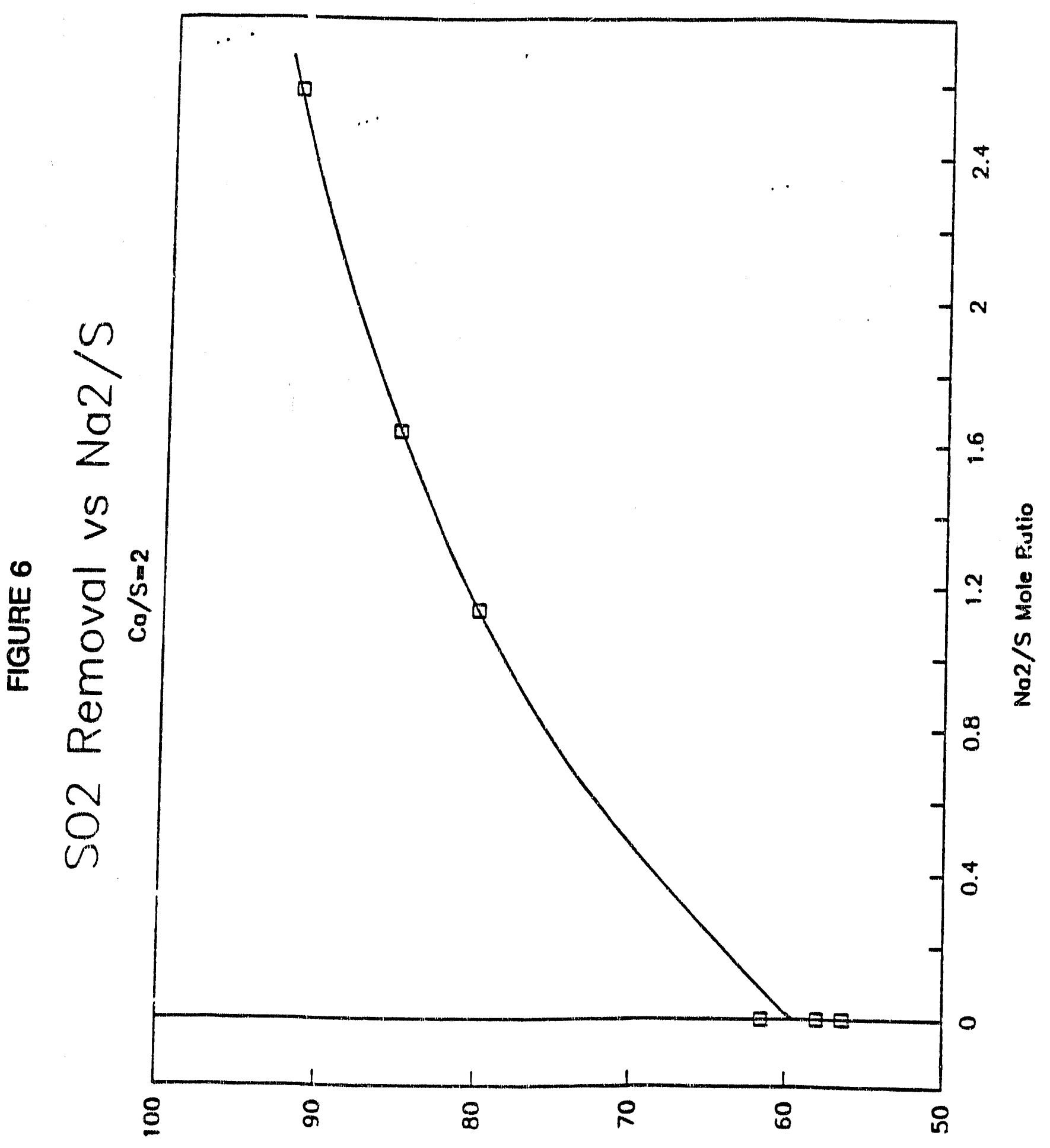

lonoway zOS luasad 
FIGURE 7

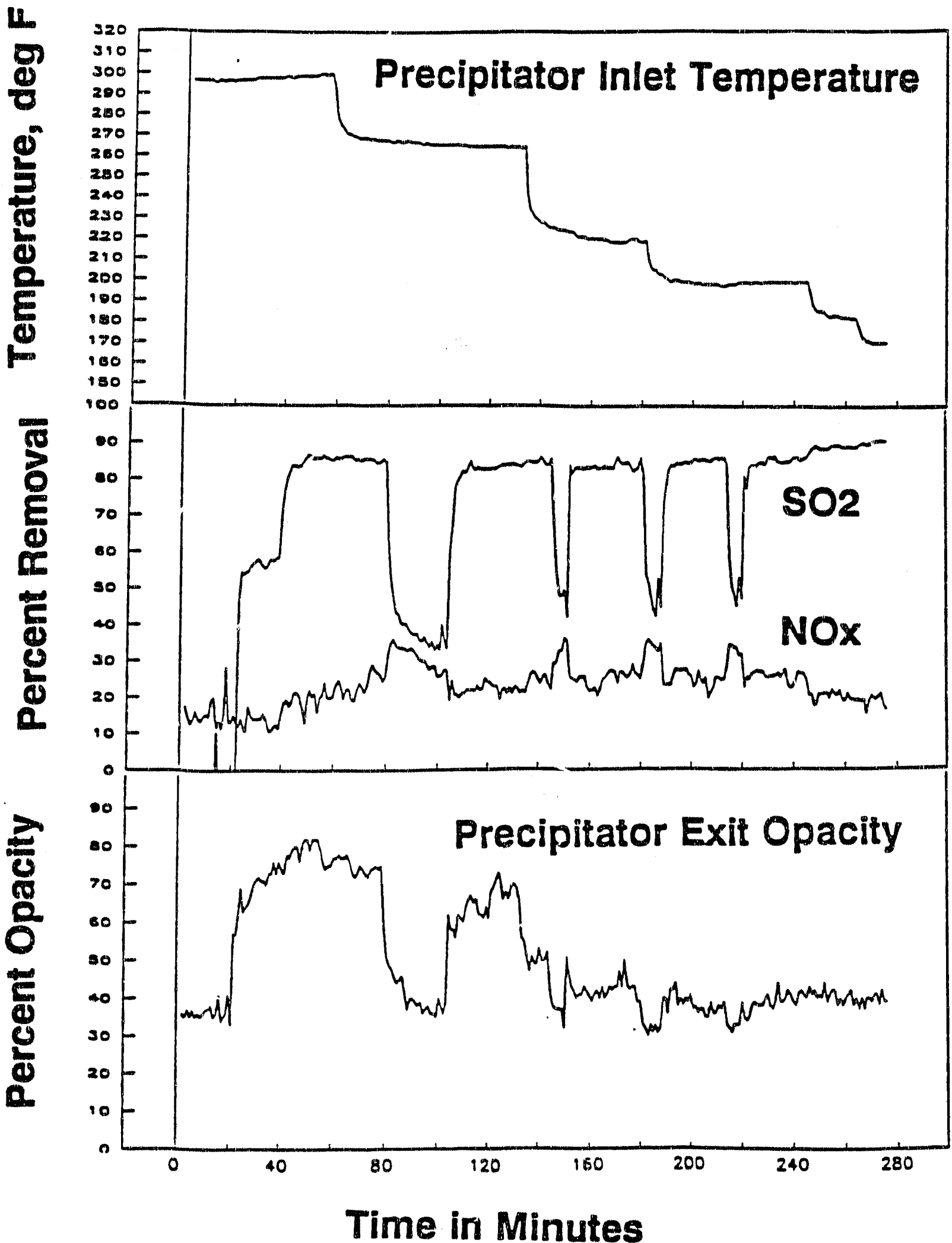


FIGURE 8

\section{EFFECT OF SORBENT MOLE RATIOS ON SO2 REMOVAL.}

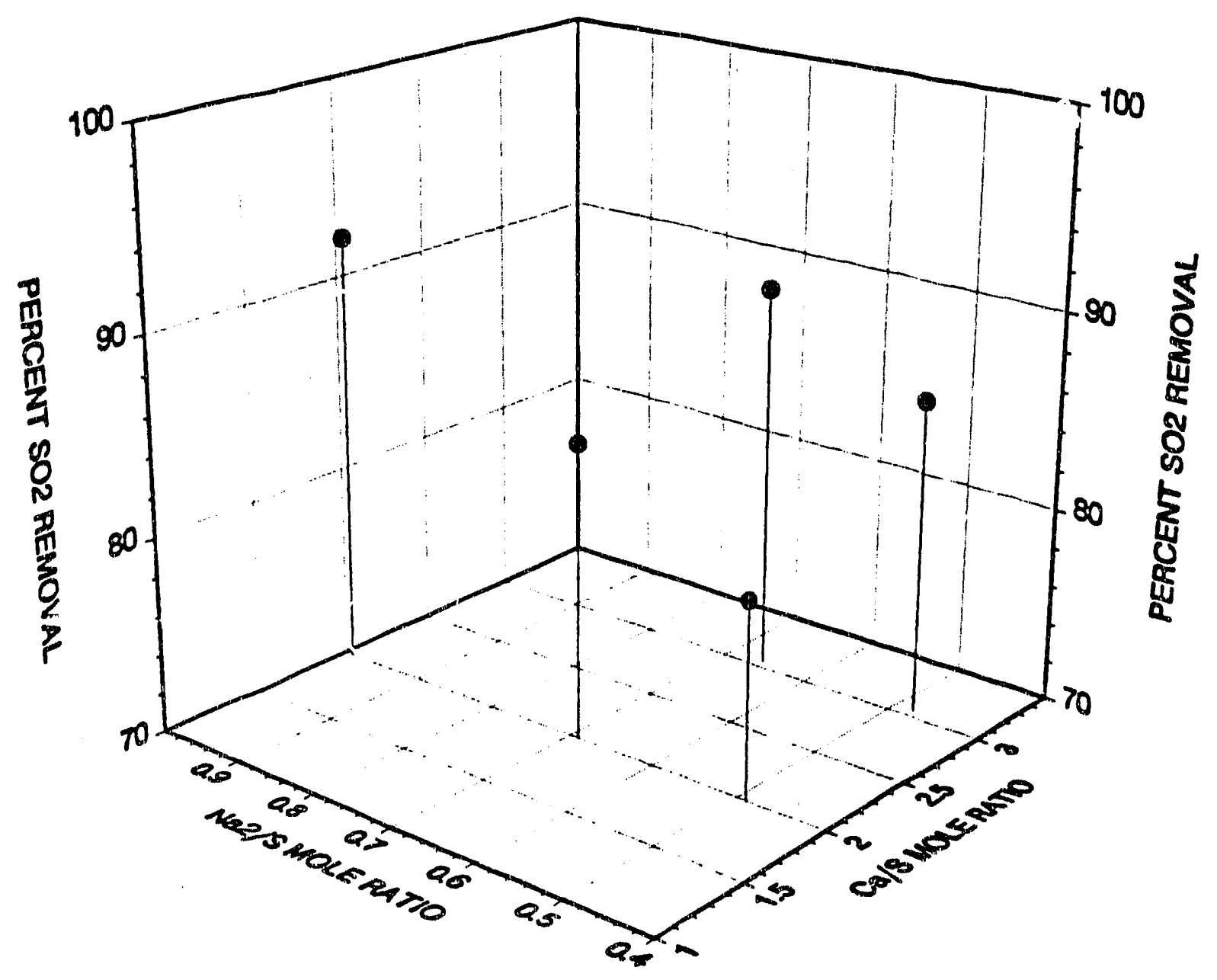


FIGURE 9

EFFECTIVENESS OF SODIUM SORBENTS

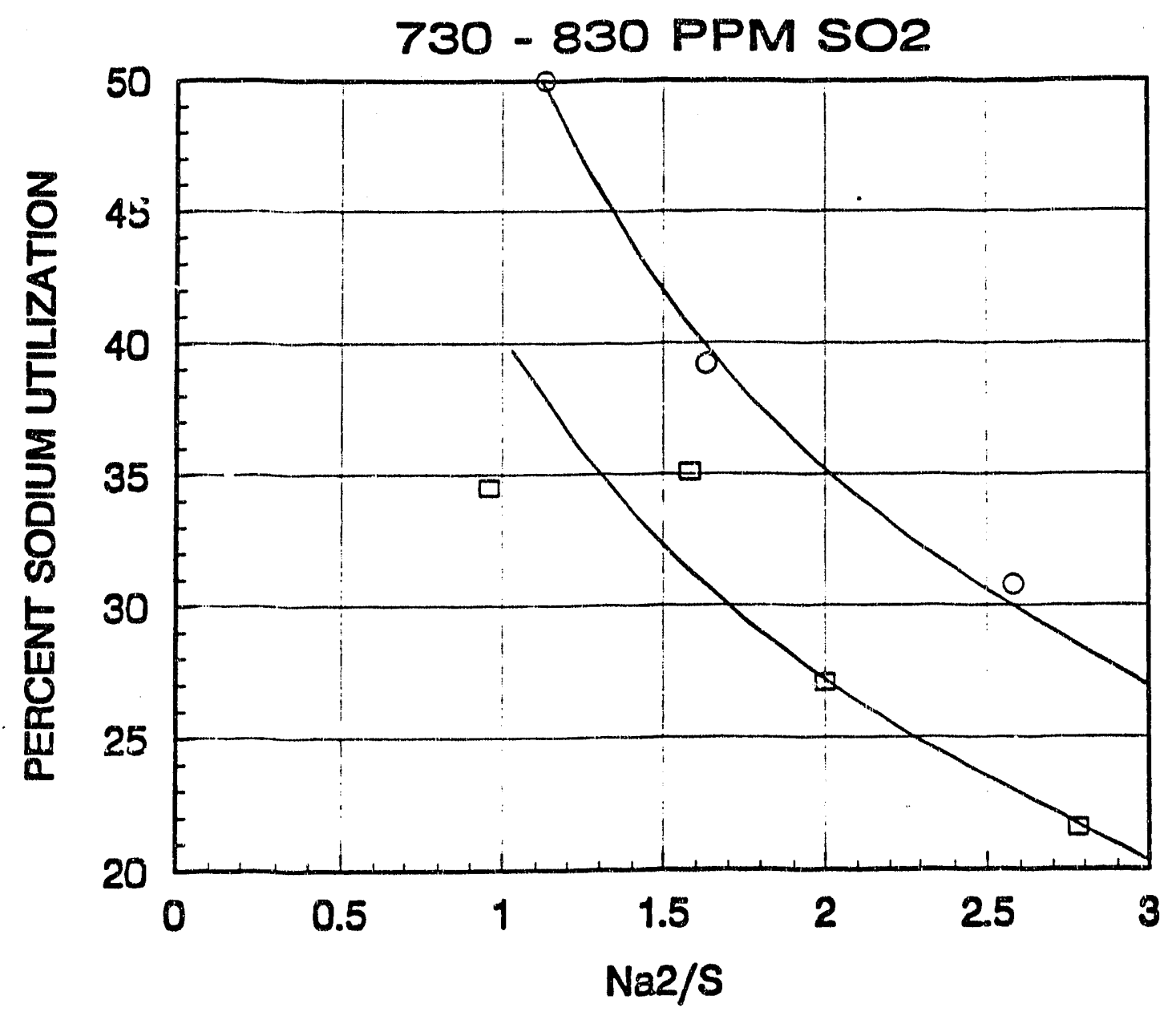

O BICARBONATE SESQUICARBONATE 
FIGURE 10

\section{EFFECT OF INLET SO2 CONCENTRATION ON SO2 REMOVAL BY HYDRATE INJECTION}

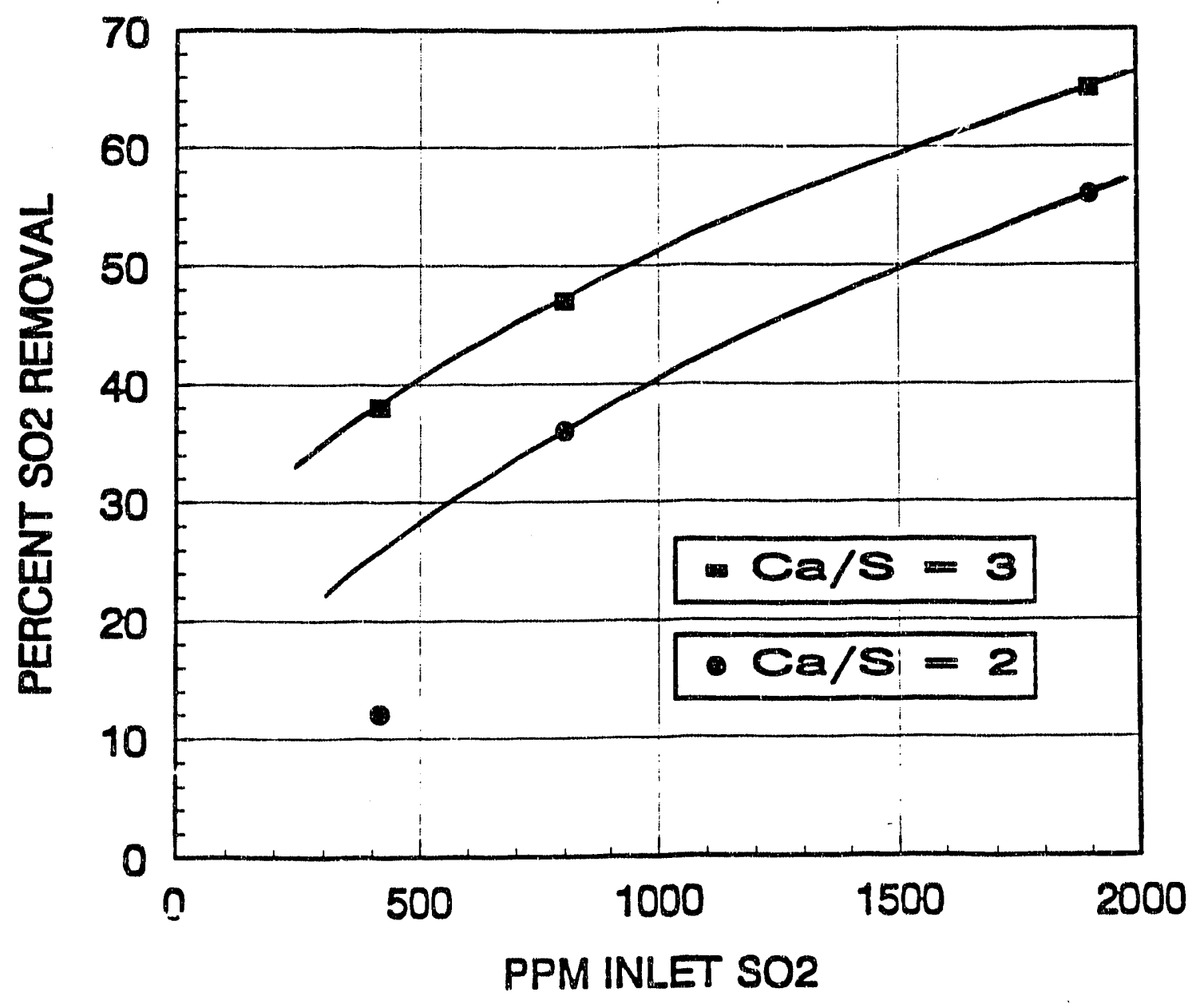



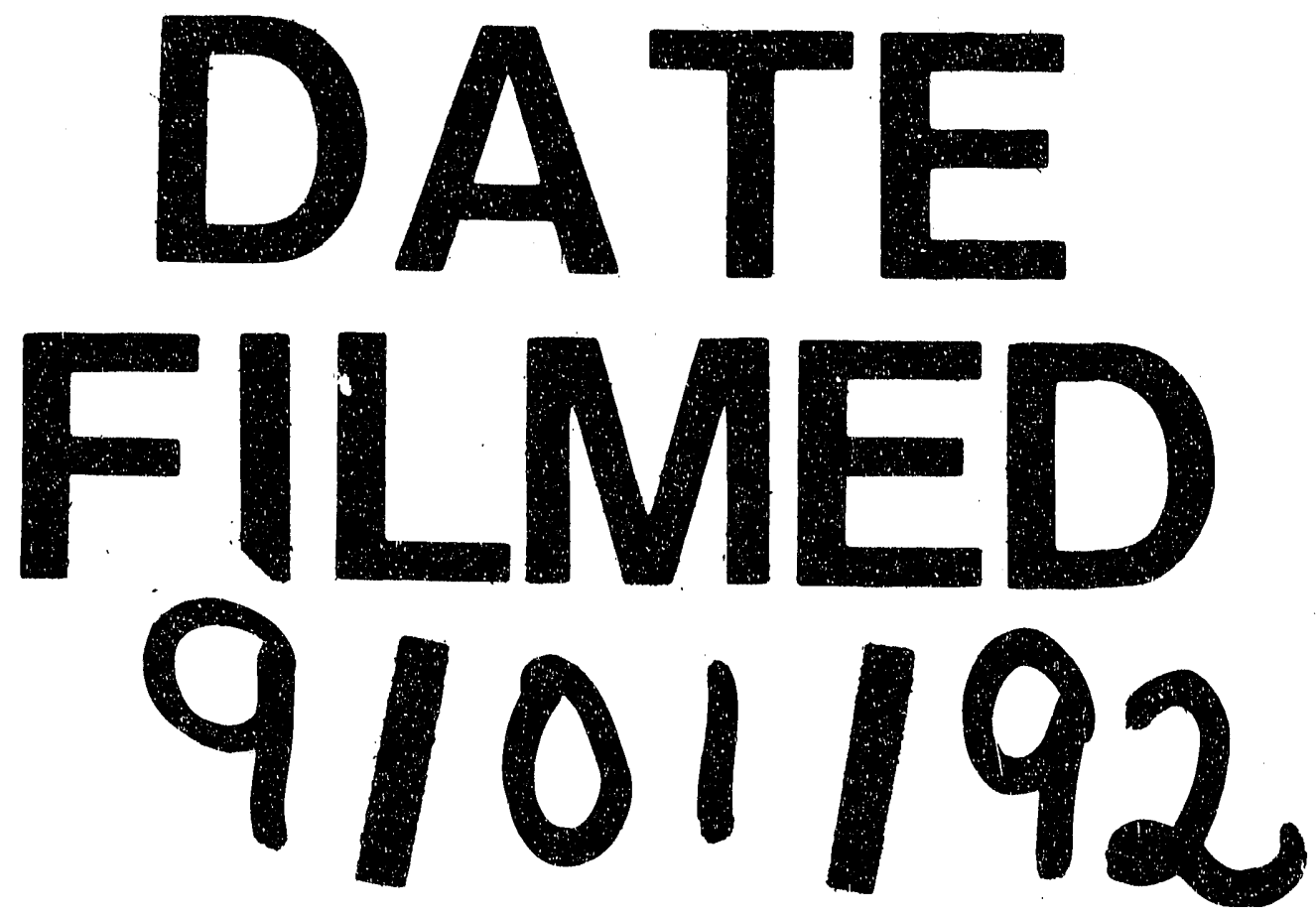

I 


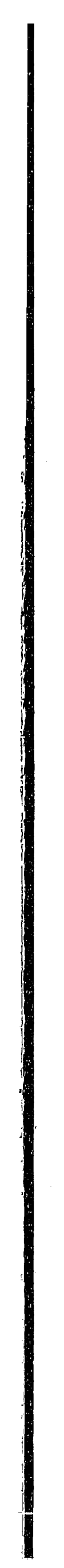

